\title{
Association Study of Resistance to Soilborne wheat mosaic virus in U.S. Winter Wheat
}

\author{
Dadong Zhang, Guihua Bai, Robert M. Hunger, William W. Bockus, \\ Jianming Yu, Brett F. Carver, and Gina Brown-Guedira
}

First, second, and fifth authors: Department of Agronomy, Kansas State University, Manhattan 66506; second author: United States Department of Agriculture-Agricultural Research Service (USDA-ARS) Hard Winter Wheat Genetics Research Unit, Manhattan, KS 66506; third author: Department of Entomology and Plant Pathology, Oklahoma State University, Stillwater 74078; fourth author: Department of Plant Pathology, Kansas State University, Manhattan 66506; sixth author: Department of Plant and Soil Sciences, Oklahoma State University, Stillwater 14078; and seventh author: USDA-ARS Plant Science Research Unit, Raleigh, NC 27695. Accepted for publication 25 April 2011.

\section{ABSTRACT}

Zhang, D., Bai, G., Hunger, R. M., Bockus, W. W., Yu, J., Carver B. F., and Brown-Guedira, G. 2011. Association study of resistance to Soilborne wheat mosaic virus in U.S. winter wheat. Phytopathology 101:1322-1329.

Soilborne wheat mosaic virus (SBWMV) is one of the most important winter wheat pathogens worldwide. To identify genes for resistance to the virus in U.S. winter wheat, association study was conducted using a selected panel of 205 elite experimental lines and cultivars from U.S. hard and soft winter wheat breeding programs. Virus symptoms were evaluated twice in virus-infected fields for the panel at Manhattan, KS in spring 2010 and 2011 and for a subpanel of 137 hard winter wheat accessions at Stillwater, OK in spring 2008. At the two locations, 69.8 and $79.5 \%$ of cultivars were resistant or moderately resistant to the disease, respectively. After 282 simple-sequence repeat markers covering all wheat chromosome arms were scanned for association in the panel, marker Xgwm469 on the long arm of chromosome 5D (5DL) showed a signifi- cant association with the disease rating. Three alleles (Xgwm469-165bp, $-167 b p$, and $-169 b p$ ) were associated with resistance and the null allele was associated with susceptibility. Correlations between the marker and the disease rating were highly significant $(0.80$ in Manhattan at $P<$ 0.0001 and 0.63 in Stillwater at $P<0.0001$ ). The alleles Xgwm469-165bp and $X g w m 469-169 \mathrm{bp}$ were present mainly in the hard winter wheat group, whereas allele Xgwm469-167bp was predominant in the soft winter wheat. The 169 bp allele can be traced back to 'Newton', and the 165 bp allele to Aegilops tauschii. In addition, a novel locus on the short arm of chromosome 4D (4DS) was also identified to associate with the disease rating. Marker Xgwm469-5DL is closely linked to SBWMV resistance and highly polymorphic across the winter wheat accessions sampled in the study and, thus, should be useful in marker-assisted selection in U.S. winter wheat.

Additional keywords: association mapping, Triticum aestivum.
Soilborne wheat mosaic virus (SBWMV) is a destructive pathogen of wheat (Triticum aestivum). It was first described in Illinois in the United States (21) and now can be found in most winter wheat-growing regions throughout the world (9). Natural infection of SBWMV in wheat plants occurs in roots through its vector, an obligate parasite soilborne plasmodiophorid protist, Polymyxa graminis Ledingham (2). A wet fall period and a prolonged cool period in spring are conducive to disease development (8). Infected wheat seedlings usually show symptoms, including mild green to yellow mosaic areas, yellow-green mottling, and dashed and parallel streaks. Stunting can be moderate to severe, depending on cultivar (10).

After infection, yellow leaves and stunted plants cause significant reduction in tiller number, kernel size, and kernel weight and ultimately result in significant yield losses in most cases $(4,10)$. Infected seedlings, however, can recover to some extent as the season progresses and temperature warms; late growth occurs in some environments (12). In the United States, yield losses due to the disease can be up to $80 \%(4,24,30)$.

Corresponding author: G. Bai; E-mail address: guihua.bai@ars.usda.gov

* The $\boldsymbol{e}$-Xtra logo stands for "electronic extra" and indicates that the online version contains four supplemental figures and two supplemental tables.

doi:10.1094/PHYTO-02-11-0041

This article is in the public domain and not copyrightable. It may be freely reprinted with customary crediting of the source. The American Phytopathological Society, 2011.
Chemical measures to control this disease are not practical. For example, soil fumigation may significantly reduce the inocula of $P$. graminis but its high cost, threat to animal safety, and ecological damage render it unacceptable as a routine disease control practice. Crop rotation is also not an effective option because virus-containing resting spores of $P$. graminis can survive for decades in the soil and can be distributed by wind, water, and machinery (6). Therefore, growing resistant cultivars is the only effective measure to control the disease $(8,31)$. Since several epidemics in the $1970 \mathrm{~s}$, breeding for resistance to SBWMV has become one of the major objectives for many winter wheat breeding programs. Resistant cultivars have been continuously released to replace susceptible cultivars in commercial production (4).

Although one to three genes for SBWMV resistance in wheat have been documented $(2,12,26,32)$, a single dominant resistance gene was frequently reported in winter wheat cultivars such as 'Shawnee', 'Centrurk', 'KS73256' (23), 'Arthur 71', 'Homestead', 'Tascosa' and 'Newton' (22). A single gene conferring SBWMV resistance was mapped independently on the long arm of wheat chromosome 5D (5DL) of the hard red winter wheat 'Karl 92' (27) and Aegilops tauschii-derived germplasm 'KS96WGRC40' (12). In addition, a gene ( $\mathrm{Sbml}$ ) for resistance to Soilborne cereal mosaic virus (SBCMV), which has $70 \%$ homology to SBWMV (11), was also mapped on chromosome arm 5 DL in U.K. wheat 'Cadenza' (3). Simple-sequence repeat (SSR) marker Xgwm469-5DL was found to co-segregate with the 
SBCMV reaction (31). However, whether the same locus confers SBCMV and SBWMV resistance remains unknown.

Association studies have been used successfully to identify genetic variants accounting for complex traits in humans $(13,20)$. In plants, this approach has been used extensively to validate and discover quantitative trait loci (QTL) or genes for important traits and to map candidate genes (41). Compared with conventional biparental linkage mapping, association analysis has the capability to exploit recombination events over multiple breeding cycles and encompass a diverse array of germplasm $(25,41)$ without the need for developing new mapping populations. With the significant improvements in methodology to increase statistical power and control false positive rates $(15,37,39)$, association studies have been used successfully to identify genes or QTL of interest in many plant species, including Arabidopsis $(1,29,40)$, maize $(17,37,39)$, potato $(19)$, and wheat (34).

Although some studies have been conducted on inheritance of resistance to SBWMV in U.S. wheat cultivars, identification of specific SBWMV resistance genes present in diverse winter wheat breeding materials have not been documented, other than for 'Karl 92' and 'KS96WGRC40'. Information on gene distribution and effect, and closely linked markers for these genes, will facilitate marker-assisted deployment of SBWMV resistance genes in breeding programs. The objectives of this study were to (i) classify a representative and contemporary sample of U.S. winter wheat for resistance to SBWMV, (ii) determine the genetic loci controlling the disease resistance, and (iii) identify DNA markers linked to the loci for marker-assisted selection (MAS).

\section{MATERIALS AND METHODS}

Plant materials. The association mapping population of 205 wheat accessions (Supplemental Table 1) included 137 hard winter wheat (HWW) and 68 soft winter wheat (SWW) experimental lines and major cultivars from the corresponding U.S. production regions selected by removing full-sib lines from six 2008 HWW and SWW nurseries (38). All seed for DNA isolation and disease evaluation were derived from a single plant of each accession in the greenhouse to minimize within-line heterogeneity.

DNA extraction and marker analysis. Procedures for tissue collection, DNA extraction, and polymerase chain reaction (PCR) amplification were described previously (38). In total, 282 SSR markers were used to genotype the population. These markers were selected from a set of 2,000 SSR markers according to quality of PCR product, polymorphic information content (PIC), and even chromosome distribution based on available data from our laboratory and from previously published maps (38). In addition, markers previously reported to be associated with resistance to SBWMV and SBCMV were also analyzed. PCR products were analyzed in an ABI3730 DNA Sequencer (Applied Biosystems, Foster City, CA) following the previously described procedure (38). The total number of alleles, major allele frequency, and PIC of an individual marker were analyzed using PowerMaker v3.25 (18).

Disease evaluation. All 205 wheat genotypes were evaluated twice for SBWMV resistance in the field at the Kansas State University Rocky Ford Research Farm at Manhattan in spring 2010 and 2011. A subset of 137 of these HWW accessions were also evaluated for disease reaction at the Field Research Services Station of Oklahoma State University at Stillwater in spring 2008. In both locations, the experiment was planted in the nurseries in numeric order with two replicates (one 3 -ft row per replicate) of each accession. A previously described rating system $(12,23)$ was used to evaluate disease damage at tillering stage (Feekes growth stage 3) according to overall leaf symptoms in each row: resistant (R), no mottling on the leaves and plants not stunted; moderately resistant (MR), very slight mottling and no stunting; moderately susceptible (MS), obvious mottling with some stunting; and susceptible (S), severe mottling and stunting. A corresponding numeric rating system (a 1-to-4 scale with 1 as resistant, 2 as moderately resistant, 3 as moderately susceptible, and 4 as susceptible) was transformed for association analysis. Seedlings with obvious disease symptoms were randomly sampled from the disease nurseries for testing the presence of SBWMV and Wheat spindle streak mosaic virus (WSSMV) in the Plant Disease Diagnostic Laboratories of Department of Plant Pathology, Kansas State University, Manhattan and Department of Entomology and Plant Pathology, Oklahoma State University, Stillwater using a compound direct-labeled enzyme-linked immunosorbent assay (ELISA) kit (Agdia, Inc. Elkhart, IN).

Association analysis. Association analyses were conducted separately for the complete set of 205 winter wheat accessions (hereafter called fullpanel) phenotyped at Manhattan, KS and the subset of 137 winter wheat accessions (hereafter called subpanel) phenotyped in both Manhattan, KS, and Stillwater, OK. Kinship matrix $(\mathrm{K})$ and population structure $(\mathrm{Q})$ of the fullpanel were established previously and the subpanel was reevaluated in this study using the same method (38).

Association analysis was conducted for two rounds for each subpanel. First, three models $(\mathrm{Q}, \mathrm{K}$, and mixed $[\mathrm{Q}+\mathrm{K}])$ were tested for fitness based on Bayesian Information Criterion (BIC) values following Yu et al. (37) and Zhang et al. (39). The vector of phenotype $y$ was calculated using the mixed model for $\mathrm{Q}+\mathrm{K}$ method as follows: $y=\mu+\mathrm{Q} v+\mathrm{Z} u+e$, where $\mu$ is a vector of intercepts, $v$ is a vector of population effects, $u$ is a vector of random polygene background effects, $e$ is a vector of residual effects, $\mathrm{Q}$ is a matrix defining the subpopulation membership relating $y$ to $v$, and $\mathrm{Z}$ is an incidence matrix relating $y$ to $u$. After two genes were identified from the first round of analysis, a second round of association analysis was conducted to further test whether the two genes were independent of each other by adding the most significant marker locus detected in the first round into the $\mathrm{Q}$ matrix as follows: $y=\mu+\mathrm{Q} v+\mathrm{M} s+\mathrm{Z} u+e$, where $\mathrm{M}$ is the frequency of the most significant marker alleles relating $y$ to $s$, which is detected in the first-round analysis. To minimize false-positive associations caused by rare alleles, all alleles with a frequency $<10$ counts were excluded in kinship and population structure estimations as well as association computation. All analyses were conducted using PROC MIXED in SAS (ver. 9.1.2; SAS Institute Inc., Cary, NC). A threshold of $P<0.0001$ was set to claim alleles that were significantly associated with SBWMV resistance.

A distance-based cluster analysis (neighbor-joining $[\mathrm{NJ}]$ tree) of all wheat accessions was conducted by PowerMarker v. 3.25 (18) using the unweighted pair-group method with arithmetic averages of Nei's genetic distance (28) and all genotypic data. Linkage disequilibrium (LD) was evaluated using Tassel version $2.1(5)$.

\section{RESULTS}

Reactions of U.S. elite winter wheat accessions to infection by SBWMV. ELISA absorbance values for SBWMV were 2.34 to 3.24 for the seedling samples from Manhattan and 2.28 to 3.00 for the seedling samples from Stillwater. WSSMV was detected in $\approx 50 \%$ samples from Stillwater, OK with absorbance readings of 1.46 to 2.61 but not detected in the samples from Manhattan, KS.

Among 205 accessions tested in Manhattan, the frequencies of resistant ( $\mathrm{R}$ and $\mathrm{MR}$ ) and susceptible (MS and $\mathrm{S}$ ) accessions were 70 and $30 \%$ in both years (Fig. 1A). Similar ratios of ratings were observed for hard $\left(\chi^{2}=0.53, P=0.34\right)$ and soft $\left(\chi^{2}=0.90, P=\right.$ 0.47 ) winter wheat cultivars (Fig. 1A). Repeatability between two years' data was high, with a correlation coefficient of $0.84(P<$ 0.0001).

In Stillwater, more resistant accessions and fewer susceptible accessions were observed than from the same set of accessions 
tested in Manhattan, with frequencies of $79.5 \%$ resistant ( $\mathrm{R}$ and MR), and $20.5 \%$ susceptible (S and MS) (Fig. 1B). The correlation coefficient was $0.82(P<0.0001)$ for disease scores between the two replicates in Stillwater and $0.62(P<0.0001)$ for mean scores between the Stillwater and Manhattan.

Markers closely linked to the SBWMV resistance gene. Among statistical models tested, the $\mathrm{Q}+\mathrm{K}$ model consistently demonstrated the smallest BIC value in both fullpanel and subpanel (Supplemental Table 2) and, thus, was employed in all association calculations. In the first-round analysis, four markers (Xgwm469, Xgwm608, Xwmc48, and Xwmc89) were significantly associated with disease ratings of the fullpanel from both years. Xgwm469 was the most significant marker with an extremely low $P$ value, whereas the other three markers showed only marginal significance at $-\log _{10}(P$ value $)=4$ (Fig. 2$)$. Although the marker
Xgwm469 amplified a total of 22 fragments (alleles) across the 205 wheat accessions, only 3 of them $(165,167$, and $169 \mathrm{bp})$ (Supplemental Figure 1) were significantly correlated with SBWMV resistance, with $P$ values ranging from $1.69 \mathrm{e}-55$ to 1.06e-15 (Figs. 2 and 3). Allele frequencies for the three alleles varied in the 205 accessions: $5 \%$ (165 bp), 24\% (167 bp), and $38 \%$ (169 bp) (Fig. 3). Disease ratings of the accessions carrying any one of the three alleles were lower. In the 2010 experiment, the mean disease ratings were 1.3 for $165 \mathrm{bp}, 1.5$ for $167 \mathrm{bp}$, and 1.4 for $169 \mathrm{bp}$ and those ratings were even slightly lower in the 2011 experiment; in contrast, the mean disease rating of both years over those accessions without any of the three alleles was 3.3 (Fig. 4). A similar pattern was observed when the subpanel was analyzed separately based on disease data from both Manhattan and Stillwater locations. Correlations between marker

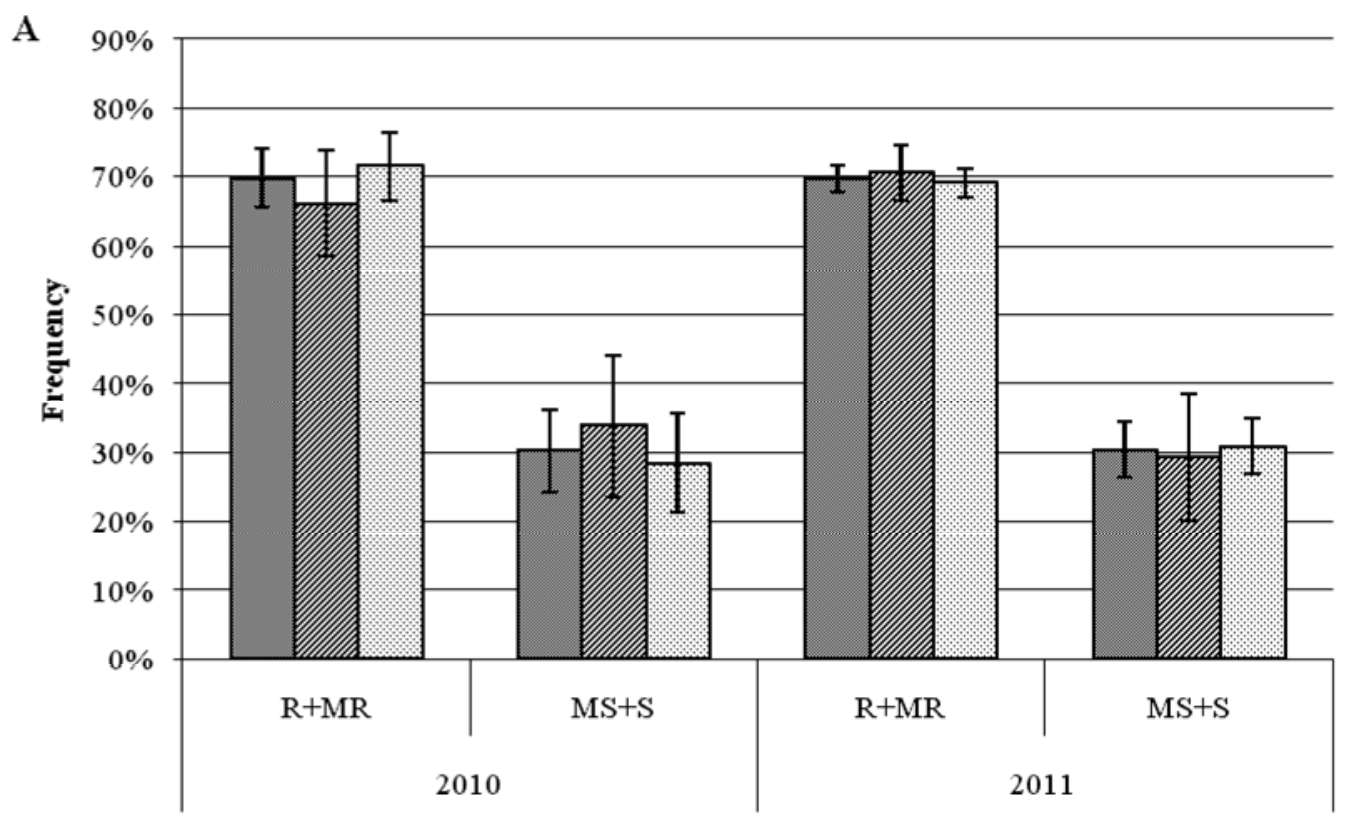

口HWW and SWW gSWW घHWW

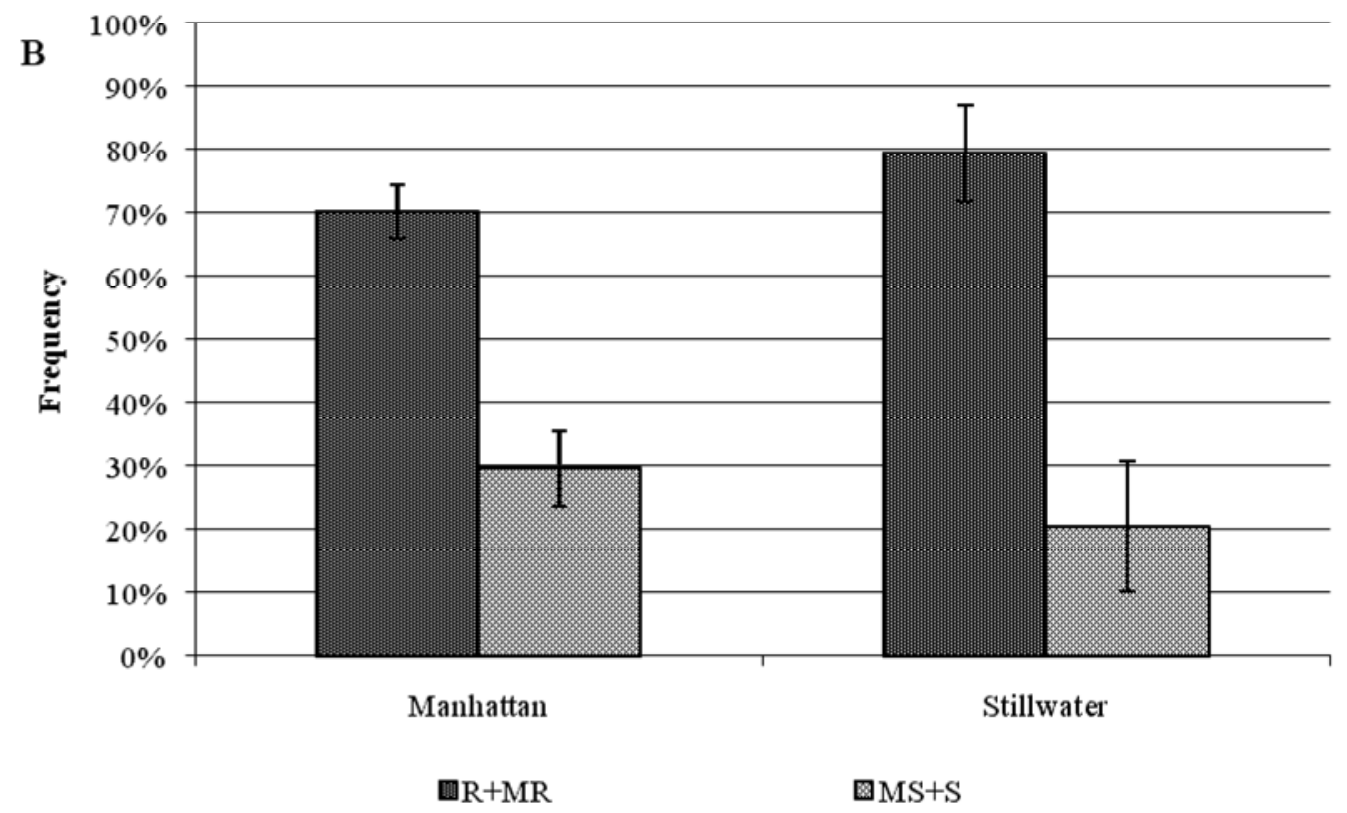

Fig. 1. Frequency distribution of wheat accessions in response to Soilborne wheat mosaic virus infection. A, Subpanel of 68 soft winter wheat (SWW), subpanel of 137 hard winter wheat (HWW), and the fullpanel of 205 accessions combined from the hard and soft subpanels evaluated in spring 2010 and 2011 at Manhattan, KS; and B, subpanel of 137 HWW evaluated at both Manhattan, KS, and Stillwater, OK. R+MR refer to resistant (R) and moderately resistant (MR) genotypes and MS+S refer to moderately susceptible (MS) and susceptible (S) genotypes. 
Xgwm469 and disease rating were $>0.79(P<0.0001)$ for the fullpanel and subpanel in Manhattan in both years and was 0.62 $(P<0.0001)$ for the subpanel tested in Stillwater. The remaining three markers, Xgwm608-168bp, Xwmc48-209bp, and Xwmc89$193 \mathrm{bp}$, had frequencies of $5.4,57.6$, and $56.1 \%$, respectively, in the fullpanel but they were not significant in the subpanel (Fig. 2).

To test whether other marker loci were independent from Xgwm469, a second round of association analysis was conducted by fixing the marker Xgwm469 into Q matrix. The result from both rounds of analyses was similar and markers Xgwm608$168 b p, X w m c 48-209 b p$, and $X w m c 89-193 b p$ remained significant in the fullpanel (Supplemental Figure 2), indicating that they were independent from Xgwm469.

The extents of LD were examined for two regions in chromosomes 4D and 5D that harbor significant markers for SBWMV resistance (Supplemental Figure 3). Xgwm565 and Xcfd10 at $\approx 20$

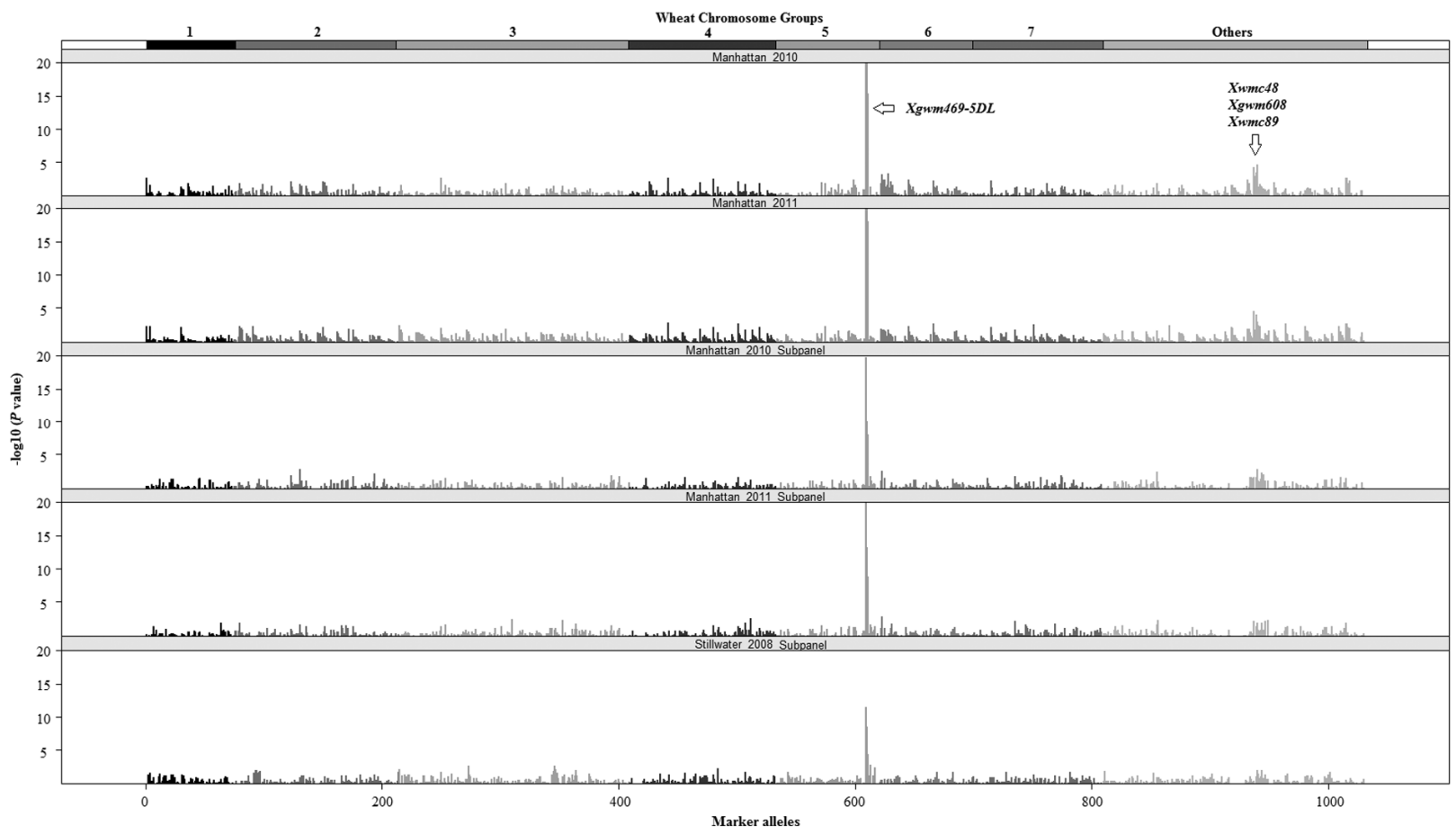

Fig. 2. First round of association scanning for wheat Soilborne wheat mosaic virus resistance using 282 genome-wide simple-sequence repeat markers. Association studies were conducted using 2 years' disease data (spring 2010 and 2011) collected from Manhattan, KS for the fullpanel of 205 winter wheat accessions and a subpanel of 137 hard winter wheat accessions and using the disease data collected from Stillwater, OK in spring 2008.

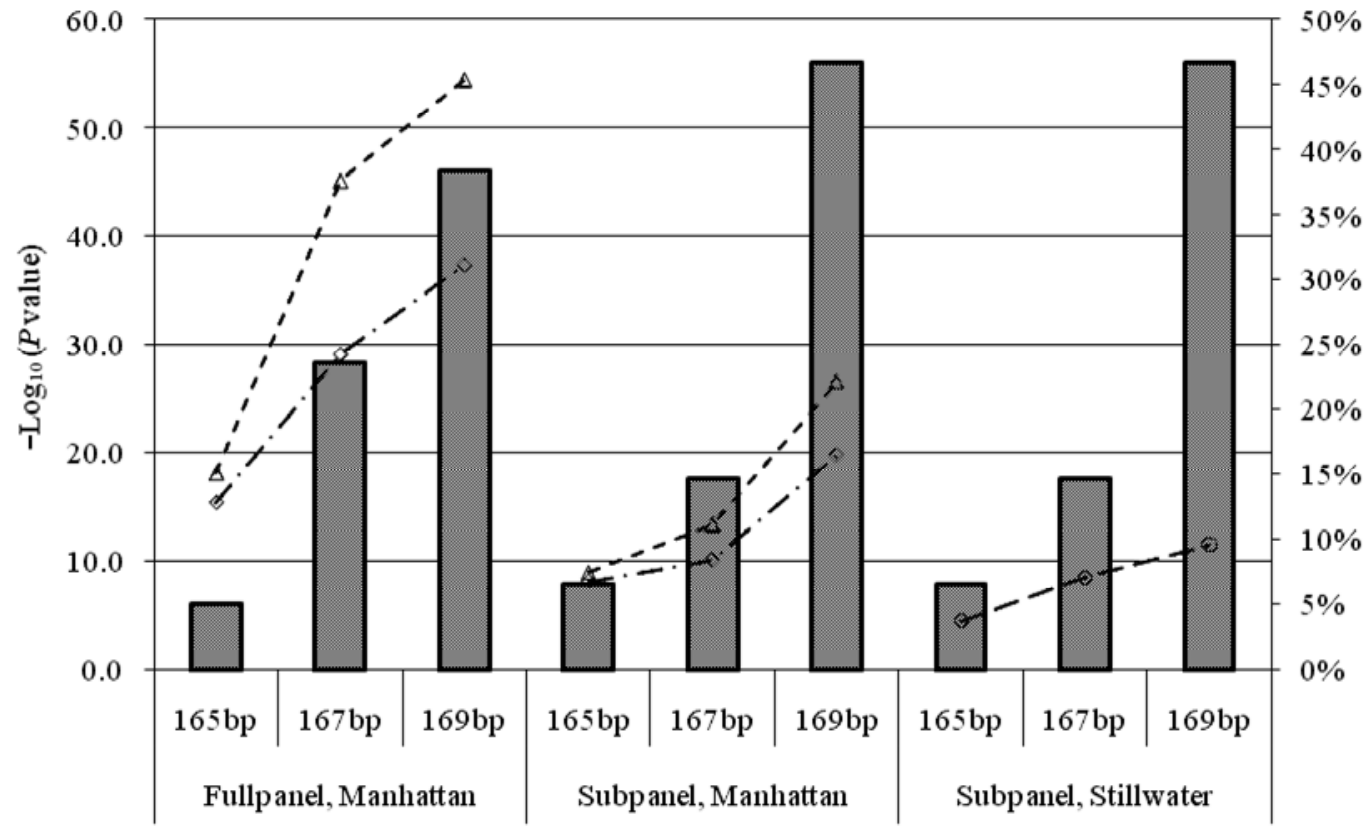

$$
\begin{array}{ll}
\square \text { Allele frequency } & -\diamond--\log _{10} \text { (Pvalue), } 2010 \\
--\diamond--\log _{10}(P \text { value }), 2011 & -\bullet--\log _{10} \text { (Pvalue), } 2008
\end{array}
$$

Fig. 3. $-\log _{10}(P$ value $)$ and frequencies of the three alleles of Xgwm469 associated with resistance to Soilborne wheat mosaic virus based on the fullpanel tested in Manhattan, KS and the subpanel tested both in Manhattan, KS and Stillwater, OK. 
centimorgans (cM) apart flank Xgwm469 on 5D and are in a significant LD block $(P<0.001)$. Another three markers on $4 \mathrm{D}-$ $X w m c 89, X w m c 48$, and $X g w m 608$ - were very close to each other and spanned a narrow distance of $4.1 \mathrm{cM}$. The LD level for the three markers was also significant at $P<0.001$.

Allele distribution across populations. The predominant alleles of Xgwm469 associated with resistance were different between HWW and SWW (Table 1; Supplemental Figure 4). The 165 and $169 \mathrm{bp}$ alleles were more frequently found in HWW lines, whereas the $167 \mathrm{bp}$ allele was more common in SWW (Table 1). Among the 10 accessions that carried the $165 \mathrm{bp}$ allele, only one was a SWW. In all, $\approx 81 \%$ accessions carrying 169 bp alleles were HWW $\left(\chi^{2}=15.17, P=0.0001\right)$ and $\approx 60 \%$ of accessions with 167 bp allele were $\operatorname{SWW}\left(\chi^{2}=6.56, P=0.01\right)$ (Table 1).

Within each market class, accessions were further divided into subgroups (38), and differences in allele frequencies also were observed among the subgroups. In HWW, a subgroup derived from crosses involving 'Jagger' contained the highest proportion of accessions carrying the alleles associated with resistance, especially the 169 bp allele (Table 1). In SWW, 76.7\% of accessions from the "North" subgroup, which primarily consisted of entries from breeding programs in Illinois, Indiana, and Ohio, contained alleles associated with resistance. This was greater than the observed frequency in the "South" subgroup (57.8\%), with entries from programs in Mid-Atlantic and southeastern states (Table 1).

Pedigree analysis traced most accessions carrying the $165 \mathrm{bp}$ allele back to A. tauschii (Fig. 5). 'OK Bullet,' its sister line 'OK02522W', and its reselection 'OK00514-05806' amplified the $X g w m 469-165 b p$ allele and were selected from the cross between 'Jagger' (Xgwm469-169bp) and 'KS96WGRC39'. 'KS96WGRC39' amplified the 165-bp allele, which was derived from the A. tauschii accession (TA2460). 'KS96WGRC40' and 'KS90WGRC10' are also A. tauschii derivatives and were one of the parents for the several other lines that amplified the $165 \mathrm{bp}$ allele (Fig. 5). Marker analysis confirmed that 'KS96WGRC39', 'KS96WGRC40', and 'KS90WGRC10' all amplified the same 165 bp allele by $X g w m 469$.

\section{DISCUSSION}

SBWMV has been detected in winter wheat-growing areas worldwide (9). In the United States, SBWMV was reported to cause yield losses in both HWW- and SWW-growing areas of the Great Plains and the eastern United States $(4,8,36)$. In the last decade, the disease has been detected in the state of New York and other regions where it had not been reported previously (8), indicating that SBWMV disease remains a challenge for winter wheat production in much of the country. In this study, U.S. elite winter wheat breeding lines and cultivars from both HWW- and SWW-growing regions were evaluated for resistance to SBWMV, providing timely assessment of the levels of resistance in current U.S. winter wheat breeding programs as well as a guideline for effective use of the resistance genes to control the disease. At least $70 \%$ of accessions tested were resistant or moderately resistant to SBWMV in both the Kansas and Oklahoma testing locations (Fig. 1), which indicates that resistance genes have been widely distributed in U.S. winter wheat breeding programs. This high frequency of resistant accessions was observed in HWW and SWW. A high proportion of accessions with SBWMV resistance also was reported previously in SWW (8). Thus, appropriate use of the germplasm in breeding resistant cultivars can effectively

TABLE 1. Distribution of marker alleles of Xgwm469 for Soilborne wheat mosaic virus (SBWMV) resistance in different phylogenetic groups

\begin{tabular}{lcccccc}
\hline Groups & Total & $165 \mathrm{bp}$ & $167 \mathrm{bp}$ & $169 \mathrm{bp}$ & $\mathrm{R}^{\mathrm{a}}$ & Other $^{\mathrm{b}}$ \\
\hline Hard winter wheat & 137 & 9 & 20 & 64 & 93 & 44 \\
South & 40 & 3 & 7 & 16 & 26 & 14 \\
North & 36 & 0 & 4 & 16 & 20 & 16 \\
Jagger & 36 & 4 & 5 & 22 & 31 & 5 \\
Other & 25 & 2 & 4 & 10 & 16 & 9 \\
Soft winter wheat & 68 & 1 & 28 & 14 & 43 & 25 \\
South & 38 & 1 & 12 & 8 & 21 & 17 \\
North & 30 & 0 & 16 & 6 & 22 & 8 \\
\hline
\end{tabular}

a Total number of accessions that carry Xgwm469 alleles associated with SBWMV resistance.

b Total number of accessions that carry Xgwm469 alleles associated with SBWMV susceptibility.

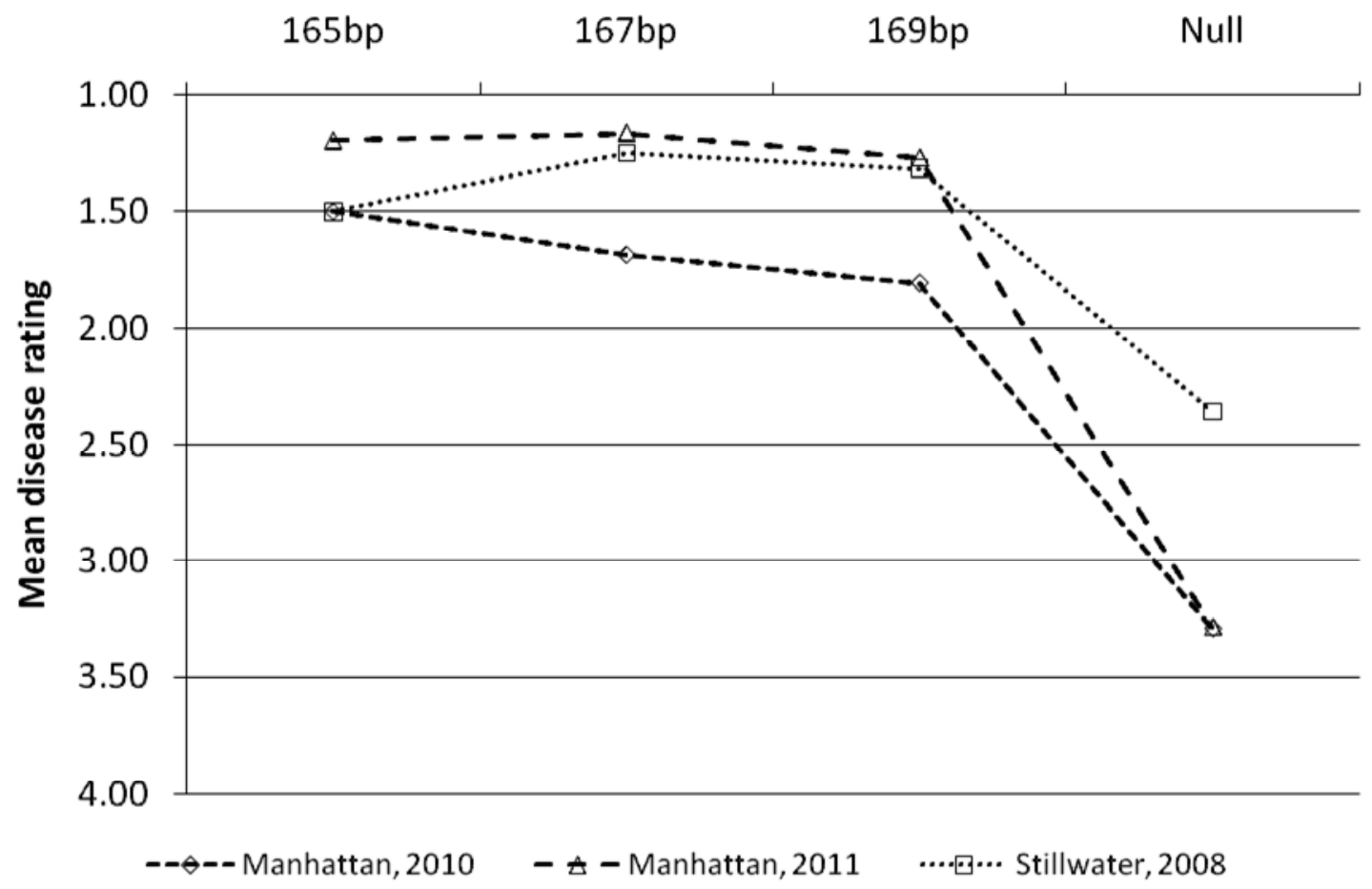

Fig. 4. Mean Soilborne wheat mosaic virus ratings of the accessions carrying the different alleles of Xgwm469 in the fullpanel and the subpanel; $1=$ most resistant and $4=$ most susceptible. 
reduce losses caused by this disease in commercial production. For example, Jagger, that was grown in Kansas and several other states for over a decade, has maintained resistance to SBWMV and has been used successfully as a source of SBWMV resistance by breeding programs throughout the Great Plains.

SBWMV is a soilborne pathogen and visual ratings of this disease can be affected by environmental conditions across test locations and years. Uniform distribution of $P$. graminis across the test site and wet soil conditions after planting are critical factors for reliable disease evaluation $(7,22)$. In this study, a high correlation was observed between 2 years' disease data from Manhattan, KS and between two locations (Stillwater, OK and Manhattan, $\mathrm{KS}$ ), indicating that disease rating was highly repeatable and, therefore, useful for association mapping. The slight variation in disease severity that was observed between locations could be due to the fact that WSSMV was also detected in the samples from the Stillwater location but not from the Manhattan location based on ELISA data. Two viruses were not visually distinguishable based on field symptoms. Wheat resistance to one of these viruses might not guarantee resistance to the other (14). The variation also may account for these shifts because the slightly more temperate climate in Oklahoma allows accessions to recover more readily in the spring from infection compared with the colder climate in Kansas. In addition, disease rating was based on visual inspection and different individuals scored the plots in two locations; thus, personal bias in scoring could also contribute to the discrepancy between locations.

Up to three genes have been reported for SBWMV resistance in wheat $(2,12,26,32)$. A single dominant gene usually is responsible for resistance in a specific cultivar (22). Separate mapping studies have identified a major locus on chromosome arm 5DL in common wheat (27) and A. tauschii (12). Using association mapping, we also identified a major gene for SBWMV in 5DL in this study and the marker $(X g w m 469)$ was significantly associated with resistance and likely tightly linked to the gene. This marker showed a highly significant association with SBWMV resistance in different years for the accessions in both the fullpanel and subpanel tested (Figs. 2 and 3), indicating that this gene is distributed across the two U.S. market classes, although the distribution of alleles associated with resistance was different in each market class.

A gene designated Sbml for resistance to SBCMV in U.K. Cadenza wheat also was located in the distal region of chromosome arm 5DL (3). Although SBCMV causes symptoms similar to those caused by SBWMV, the viruses share only $\approx 70 \%$ sequence identity and have been suggested to be classified as separate species $(11,16,35)$. Perovic et al. (31) recently reported co-segregation of Xgwm469-5DL with SBCMV resistance in DH populations derived from three resistant European cultivars, including the Sbml-carrying 'Cadenza'. In an evaluation of diverse cultivars from Europe, Asia, and the Americas, they found that the 152 and 154 bp Xgwm469 alleles were diagnostic for
SBCMV resistance conferred by the Sbml locus. Included in Perovic et al.'s study were U.S. 'Jagger' and 'Karl 92', which also are included in our study. These HWW cultivars, along with 'Newton' that is in the pedigree of 'Jagger', were determined to be resistant to SBCMV. We found that the same alleles of Xgwm469 associated with SBCMV in 'Newton', 'Jagger', and 'Karl 92' were associated with SBWMV resistance in the current study. The reported difference in allele sizes between the two studies (152 and $154 \mathrm{bp}$ versus 167 and $169 \mathrm{bp}$ ) are due to the presence of an M13 tail sequence on the forward primers used in the current study. Therefore, the current study indicated that wheat resistance to SBWMV and to SBCMV is high likely to be controlled by the same gene or tightly linked genes in 5DL.

Our association study suggests that $\mathrm{Xgwm} 469-5 \mathrm{DL}$ is tightly linked to the major SBWMV resistance locus on 5DL. Hall et al. (12) located the SBWMV resistance gene 'KS99WGRC40' to a 20.1-cM region on 5DL but did not evaluate Xgwm469 on the mapping population. The closest marker mapped by Hall et al. (13), Xcfd10, was not significant for SBWMV resistance in this study, although $X c f d 10$ and $X g w m 469$ were in the same LD block. This result indicated that $X g w m 469$ is closer to the SBWMV resistance gene than $X c f d 10$. The highly significant association of Xgwm469 and SBWMV resistance in U.S. winter wheat makes it a valuable marker for marker-assisted development of SBWMVresistant cultivars.

Although all three significant alleles of Xgwm469-5DL were found in both hard and soft wheat gene pools of this study, they are not distributed equally between HWW and SWW lines evaluated (Table 1), indicating that the major sources of resistance appearing in the two different gene pools might have different origins. The SWW accessions could be further divided into two subgroups (38), a 'North' subgroup with accessions mainly from Illinois, Indiana, and Ohio that had more resistant or moderately resistant accessions than were observed in a 'South' subgroup (Table 1), although the differences in frequency were not significant in a $\chi^{2}$ test $\left(\chi^{2}=1.40, P=0.237\right)$. The resistant accessions in the North subgroup mainly carry the 167 bp Xgwm 469 allele. The origin of the $167 \mathrm{bp}$ allele was not evident based on pedigree and remains to be determined.

The HWW Jagger has been widely used as a parent in many breeding programs of the Great Plains. 'Jagger' is resistant to SBWMV and carries the 169 bp Xgwm469-5DL allele. Cluster analysis clearly separated Jagger-related accessions into an independent subgroup (Table 1). The 'Jagger' subgroup contained the highest proportion $(86.1 \%)$ of resistant or moderately resistant accessions, with resistant accessions having primarily the $169 \mathrm{bp}$ Xgwm469-5DL allele. Thus, 'Jagger' appears to be the source of this allele in these HWW accessions. Pedigree analysis found that 'Newton' is an ancestor of 'Jagger'. Early genetic studies indicated that 'Newton' was an important source for SBWMV resistance in U.S. wheat and that the resistance gene in 'Newton' was

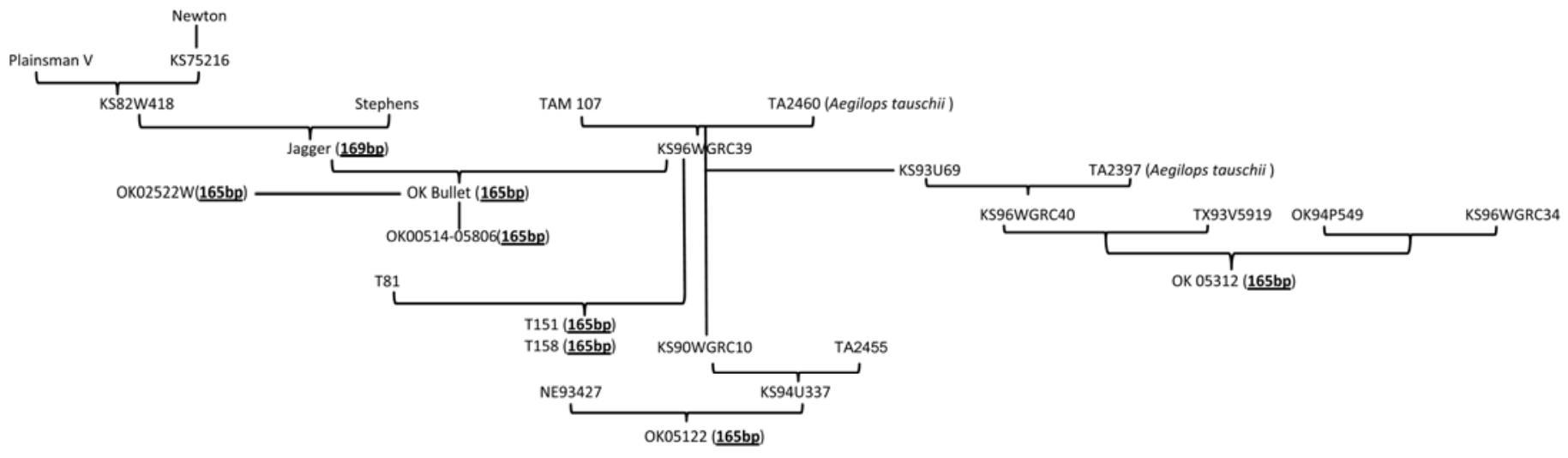

Fig. 5. Pedigree information for accessions with the Xgwm469-165bp allele. 
most likely from the Argentinean 'Klein Rendidor' $(22,23)$. Thus, the 169 bp allele in 'Jagger' most likely was derived from 'Klein Rendidor' through 'Newton' (Fig. 5).

In this study, a new allele of Xgwm469, Xgwm469-165, was identified in 10 accessions, which was not reported in a previous survey of 99 diverse wheat cultivars from different regions of the world (31). This result suggests that this allele is a new introgression in U.S. winter wheat germplasm. Among the 10 accessions, only one is a newly released cultivar ('OK Bullet') whereas all the others are recent breeding lines. These data indicate that the $165 \mathrm{bp}$ allele is a newly introduced allele in wheat breeding programs. Pedigree analysis traced the $165 \mathrm{bp}$ allele back to the wheat D-genome donor, A. tauschii (Fig. 5). SBWMV-resistant common wheat lines 'KS93WGRC10', 'KS96WGRC39', and 'KS96WGRC40', derived from crosses with different accessions of A. tauschii, are parents of wheat lines having the 165 bp allele. 'KS96WGRC40' was reported to inherit its SBWMV resistance gene from 'TA2137', an A. tauschii accession (12), which supports our result.

In the other three HWW subgroups, the 'North' subgroup contained mostly susceptible or moderately susceptible accessions. Most accessions in this subgroup came from North Dakota and Montana and did not carry any of the three alleles associated with resistance. This is expected given that SBWMV is not a major disease for wheat production in the spring wheat region of the northern United States.

More than one gene has been credited for resistance to SBWMV $(2,8,31)$. In addition to $X g w m 469-5 D L$ in this study, three other markers (Xgwm608, Xwmc48, and Xwmc89) showed significant association with SBWMV resistance (Fig. 2). All three markers were mapped within a 4.1-cM interval on the short arm of chromosome 4D (4DS) and in one LD block (33). Therefore, another new locus for SBWMV resistance is likely to reside on 4DS. Although these markers were detected only in the full panel with marginal significance (Fig. 2) and were not significant in the subpanel, they remained significant in the second round of analysis when a gene in 5DL was fixed in the model. Thus, the locus on $4 \mathrm{D}$ is more likely to be independent from the one in 5DL. The reason that they were not significant in the HWW could be related to the reduced population size, because a small population size may significantly reduce statistical power of association analysis (41). Another, more likely, explanation is that the gene linked to the markers has only a minor effect on SBWMV. This gene may modify the expression of the 5DL gene and, thereby, produce phenotypes in the intermediate category. These markers also are possibly located far enough from the gene such that recombination between the gene and the markers diminishes the effect of the gene.

In summary, we confirmed that a major gene on 5DL, previously reported for resistance to SBCMV (32), is mainly responsible for SBWMV resistance in U.S. winter wheat and estimated that $\approx 66 \%$ of current U.S. winter wheat cultivars and breeding lines that carry this gene in this study provide an effective level of resistance to SBWMV. Xgwm469, a marker closely linked to SBWMV, can predict the presence of the gene. Three alleles of Xgwm469-5DL associated with resistance might have different origins: Xgwm469-165bp, a newly identified allele in this study, was introduced from A. tauschii; Xgwm469-169bp may have originated from the Argentinean Klein Rendidor wheat; and the origin of allele $X g w m 469-167 b p$ is unknown. These three alleles should provide a breadth of genetic backgrounds for which selection of the 5DL gene will be effective. A potential new minor gene detected on chromosome 4DS also may contribute to SBWMV resistance in U.S. wheat.

\section{ACKNOWLEDGMENTS}

Mention of trade names or commercial products in this article is solely for the purpose of providing specific information and does not imply recommendation or endorsement by the United States Department of Agriculture (USDA). Contribution number 11-220-J from the Kansas Agricultural Experiment Station, Manhattan, KS. This project was supported by the National Research Initiative Competitive Grants CAP project 2011-68002-30029 from the USDA National Institute of Food and Agriculture. We thank the Plant Disease Diagnostic Laboratories of Department of Plant Pathology, Kansas State University, Manhattan for providing ELISA data.

\section{LITERATURE CITED}

1. Atwell, S., Huang, Y. S., Vilhjalmsson, B. J., Willems, G., Horton, M., Li, Y., Meng, D., Platt, A., Tarone, A. M., Hu, T. T., Jiang, R., Muliyati, N. W., Zhang, X., Amer, M. A., Baxter, I., Brachi, B., Chory, J., Dean, C., Debieu, M., de Meaux, J., Ecker, J. R., Faure, N., Kniskern, J. M., Jones, J. D., Michael, T., Nemri, A., Roux, F., Salt, D. E., Tang, C., Todesco, M., Traw, M. B., Weigel, D., Marjoram, P., Borevitz, J. O., Bergelson, J., and Nordborg, M. 2010. Genome-wide association study of 107 phenotypes in Arabidopsis thaliana inbred lines. Nature 465:627-631.

2. Barbosa, M. M., Goulart, L. R., Prestes, A., and Juliatti, F. C. 2001. Genetic control of resistance to Soilborne wheat mosaic virus in Brazilian cultivars of Triticum aestivum L. Thell. Euphytica 122:417-422.

3. Bass, C., Hendley, R., Adams, M. J., Hammond-Kosack, K. E., and Kanyuka, K. 2007. The Sbml locus conferring resistance to Soilborne cereal mosaic virus maps to a gene-rich region on 5DL in wheat. Genome 49:1140-1148.

4. Bockus, W. W., Appel, J. A., Bowden, R. L., Fritz, A. K., Gill, B. S., Martin, T. J., Sears, R. G., and Seifers, D. L. 2001. Success stories: breeding for wheat disease resistance in Kansas. Plant Dis. 85:453-461.

5. Bradbury, P. J., Zhang, Z., Kroon, D. E., Casstevens, T. M., Ramdoss, Y., and Buckler, E. S. 2007. TASSEL: software for association mapping of complex traits in diverse samples. Bioinformatics 23:2633-2635.

6. Brakke, M. K., and Langenberg, W. G. 1988. Experiences with Soilborne wheat mosaic virus in North America and elsewhere. Pages 183-202 in: Developments in Applied Biology II: Viruses with Fungal Vectors, Vol. 2. J. I. Cooper and M. J. C., Asher, eds. Association of Applied Biologists, Wellesbourne, UK.

7. Cadle-Davidson, L., and Gray, S. M. 2006. Soilborne wheat mosaic virus. The Plant Health Instructor. Online publication. doi:10.1094/PHI-I-20060424-01.

8. Cadle-Davidson, L., Sorrells, M. E., Gray, S. M., and Bergstrom, G. C. 2006. Identification of small grains genotypes resistant to Soilborne wheat mosaic virus. Plant Dis. 90:1039-1044.

9. Clover, G. R. G., Ratti, C., and Henry, C. M. 2001. Molecular characterization and detection of European isolates of Soilborne wheat mosaic virus. Plant Pathol. 50:761-767.

10. Cowger, C., and Weisz, R. 2006. Soilborne wheat mosaic and Spindle streak mosaic virus. N.C. State Univ. Ext. Publ., Raleigh.

11. Diao, A., Chen, J., Gitton, F., Antoniw, J. F., Mullins, J., Hall, A. M., and Adams, M. J. 1999. Sequences of European Wheat mosaic virus and Oat golden stripe virus and genome analysis of the genus Furovirus. Virology 261:331-339.

12. Hall, M. D., Brown-Guedira, G., Klatt, A., and Fritz, A. K. 2009. Genetic analysis of resistance to Soilborne wheat mosaic virus derived from Aegilops tauschii. Euphytica 169:169-176.

13. Hindorff, L. A., Sethupathy, P., Junkins, H. A., Ramos, E. M., Mehta, J. P., Collins, F. S., and Manolio, T. A. 2009. Potential etiologic and functional implications of genome-wide association loci for human diseases and traits. Proc. Natl. Acad. Sci. USA 106:9362-9367.

14. Hunger, R. M. 2010. Wheat soilborne mosaic. Pages 112-113 in: Compendium of Wheat Disease and Pests, 3rd ed. W. W. Bockus, R. L. Bowden, R. M. Hunger, W. L. Morrill, T. D. Murray, and R. W. Smiley, eds. American Phytopathological Society Press, St. Paul, MN.

15. Kang, H. M., Zaitlen, N. A., Wade, C. M., Kirby, A., Heckerman, D., Daly, M. J., and Eskin, E. 2008. Efficient control of population structure in model organism association mapping. Genetics 178:1709-1723.

16. Koenig, R., and Huth, W. 2003. Natural infection of wheat by the type strain of Soilborne wheat mosaic virus in a field in southern Germany. Eur. J. Plant Pathol. 109:101-103.

17. Krill, A. M., Kirst, M., Kochian, L. V., Buckler, E. S., and Hoekenga, O. A. 2010. Association and linkage analysis of aluminum tolerance genes in maize. PLoS One 5:e9958.

18. Liu, K., and Muse, S. V. 2005. PowerMarker: an integrated analysis environment for genetic marker analysis. Bioinformatics 21:2128-2129.

19. Malosetti, M., van der Linden, C. G., Vosman, B., and van Eeuwijk, F. A. 2007. A mixed-model approach to association mapping using pedigree information with an illustration of resistance to Phytophthora infestans in potato. Genetics 175:879-889.

20. Manolio, T. A., Collins, F. S., Cox, N. J., Goldstein, D. B., Hindorff, L. 
A., Hunter, D. J., McCarthy, M. I., Ramos, E. M., Cardon, L. R., Chakravarti, A., Cho, J. H., Guttmacher, A. E., Kong, A., Kruglyak, L., Mardis, E., Rotimi, C. N., Slatkin, M., Valle, D., Whittemore, A. S., Boehnke, M., Clark, A. G., Eichler, E. E., Gibson, G., Haines, J. L., Mackay, T. F., McCarroll, S. A., and Visscher, P. M. 2009. Finding the missing heritability of complex diseases. Nature 461:747-753.

21. McKinney, H. H. 1923. Investigations of the rosette disease of wheat and its control. J. Agric. Res. 23:771-800.

22. Merkle, O. G., and Smith, E. L. 1983. Inheritance of resistance to soilborne mosaic in wheat. Crop Sci. 23:1075-1076.

23. Modawi, R. S., Heyne, E. G., Brunetta, D., and Willis, W. G. 1982. Genetic studies of field reaction to wheat soilborne mosaic virus. Plant Dis. 66:1183-1184.

24. Myers, L. D., Sherwood, J. L., Siegerist, W. C., and Hunger, R. M. 1993. Temperature-influenced virus movement in expression of resistance to Soilborne wheat mosaic virus in hard red winter wheat (Triticum aestivum). Phytopathology 83:548-551.

25. Myles, S., Peiffer, J., Brown, P. J., Ersoz, E. S., Zhang, Z., Costich, D. E., and Buckler, E. S. 2009. Association mapping: critical considerations shift from genotyping to experimental design. Plant Cell 21:2194-2202.

26. Nakagawa, M., Soga, Y., Watanabe, S., Gocho, H., and Nishio, K. 1960. Genetical studies on the wheat mosaic virus. II. Genes controlling the manifestation of yellow mosaic virus in wheat. (Abstr.) Plant Breed. 30:508.

27. Narasimhamoorthy, B., Gill, B. S., Fritz, A. K., Nelson, J. C., and BrownGuedira, G. L. 2006. Advanced backcross QTL analysis of a hard winter wheat x synthetic wheat population. Theor. Appl. Genet. 112:787-796.

28. Nei, M. 1978. Estimation of average heterozygosity and genetic distance from a small number of individuals. Genetics 89:583-590.

29. Nemri, A., Atwell, S., Tarone, A. M., Huang, Y. S., Zhao, K., Studholme, D. J., Nordborg, M., and Jones, J. D. 2010. Genome-wide survey of Arabidopsis natural variation in downy mildew resistance using combined association and linkage mapping. Proc. Natl. Acad. Sci. USA 107:1030210307.

30. Nykaza, S. M., Heyne, E. G., and Niblett, C. L. 1979. Effects of wheat soilborne mosaic on several plant characters of winter wheat. Plant Dis. Rep. 63:594-598.

31. Perovic, D., Förster, J., Devaux, P., Hariri, D., Guilleroux, M., Kanyuka,
K., Lyons, R., Weyen, J., Feuerhelm, D., Kastirr, U., Sourdille, P., Röder, M., and Ordon, F. 2009. Mapping and diagnostic marker development for Soilborne cereal mosaic virus resistance in bread wheat. Mol. Breed. 23:641-653

32. Shaalan, M. I., Heyne, E. G., and Sill, W. H., Jr. 1966. Breeding wheat for resistance to Soilborne wheat mosaic virus, Wheat streak-mosaic virus, leaf rust, stem rust, and bunt. Phytopathology 56:664-669.

33. Somers, D. J., Isaac, P., and Edwards, K. 2004. A high-density microsatellite consensus map for bread wheat (Triticum aestivum L.). Theor. Appl. Genet. 109:1105-1114.

34. Stich, B., Mohring, J., Piepho, H. P., Heckenberger, M., Buckler, E. S., and Melchinger, A. E. 2008. Comparison of mixed-model approaches for association mapping. Genetics 178:1745-1754.

35. Torrance, L., and Koenig, R. 2004. Genus Furovirus. Page 1259 in: Virus Taxonomy: VIIIth Report of the International Committee on Taxonomy of Viruses. C. M. Fauquet, M. A. Mayo, J. Maniloff, U. Desselberger, and L. A. Ball, eds. Elsevier and Academic Press, San Diego, CA.

36. Verchot, J., Driskel, B. A., Zhu, Y., Hunger, R. M., and Littlefield, L. J. 2001. Evidence that Soilborne wheat mosaic virus moves long distance through the xylem in wheat. Protoplasma 218:57-66.

37. Yu, J., Pressoir, G., Briggs, W. H., Vroh Bi, I., Yamasaki, M., Doebley, J. F., McMullen, M. D., Gaut, B. S., Nielsen, D. M., Holland, J. B. Kresovich, S., and Buckler, E. S. 2006. A unified mixed-model method for association mapping that accounts for multiple levels of relatedness. Nat. Genet. 38:203-208.

38. Zhang, D., Bai, G., Zhu, C., Yu, J., and Carver, B. F. 2010. Genetic diversity, population structure, and linkage disequilibrium in U.S. elite winter wheat. Plant Genome 3:117-127.

39. Zhang, Z., Ersoz, E., Lai, C. Q., Todhunter, R. J., Tiwari, H. K., Gore, M. A., Bradbury, P. J., Yu, J., Arnett, D. K., Ordovas, J. M., and Buckler, E. S. 2010. Mixed linear model approach adapted for genome-wide association studies. Nat. Genet. 42:355-360.

40. Zhao, K., Aranzana, M. J., Kim, S., Lister, C., Shindo, C., Tang, C., Toomajian, C., Zheng, H., Dean, C., Marjoram, P., and Nordborg, M. 2007. An Arabidopsis example of association mapping in structured samples. PLoS Genet. 3:e4.

41. Zhu, C., Gore, M., Buckler, E. S., and Yu, J. 2008. Status and prospects of association mapping in plants. Plant Genome 1:5-20. 